\title{
(In)variability of Attachment in Middle Childhood: Secure Base Script Evidence in Diary Data
}

\author{
Guy Bosmans,' Magali Van de Walle,' Lien Goossens, ${ }^{2}$ and Eva Ceulemans' \\ ${ }^{\prime}$ KU Leuven, Leuven, Flanders, Belgium \\ ${ }^{2}$ Ghent University, Ghent, Belgium
}

\begin{abstract}
Secure attachment is characterised by a secure base script regarding the attachment figure as a source for support. Having such a cognitive script should affect the stability of state attachment. Specifically, incongruent attachment-related information should get assimilated to this secure base script, leading to state attachment scores that hardly fluctuate. For children without a script, state attachment should vary depending on the quality of attachment-related interactions. Two diary studies were carried out in 9- to 13-year-old children. Results suggested that with assimilation: (1) securely attached children fluctuated less in their daily attachment-related appraisals; (2) fluctuations were related to conflicts with mother; (3) this relation was stronger for less securely attached children. Consequently, these studies further support the secure base script hypothesis and provide insight into the interplay of trait and state components of attachment-related appraisals.
\end{abstract}

Keywords: attachment, secure base script, state attachment, assimilation

Bowlby (1969) developed attachment theory to understand the role of aversive early parent-child relationships in abnormal child development. To explain this association, he conjectured that children store their experiences of interactions with their parents in internal working models (IWMs). When IWMs are formed based on experiences of sensitive and responsive parenting, children become securely attached, while IWMs reflecting experienced insensitive and unresponsive parenting lead to insecure attachment (Ainsworth, Blehar, Waters, \& Wall, 1978; Bowlby, 1969). Secure IWMs are characterised by appraisals that reflect children's trust regarding a primary caregiver's availability, responsiveness, and competence to provide assistance, safety and comfort (Ainsworth, 1973). Conversely, insecure IWMs are characterised by appraisals that reflect uncertainty about parental support in general, and fear for parental rejection (anxious attachment) and/or the evaluation that it is better to solve ongoing issues without relying on the parent (avoidant attachment; Brenning, Soenens, Braet, \& Bosmans, 2011; Mikulincer \& Shaver, 2007). As insecure attachment is a fundamental transdiagnostic risk factor for psychopathology in middle childhood and beyond (e.g., Brumariu \& Kerns, 2010; DeKlyen \& Greenberg, 2008), a better understanding of children's IWM could be fundamental to develop adequate treatment strategies.

Generally, IWMs were supposed to have a trait-like effect on children's attachment-related appraisals and on their subsequent support-seeking behaviour

Address for correspondence: Guy Bosmans, Parenting and Special Education Research Group, Leopold Vanderkelenstraat 32 bus 3765, 3000 Leuven, Belgium. E-mail: guy.bosmans@ppw.kuleuven.be

Behaviour Change | Volume 31 | Number 4 | 2014 | pp. 225-242 | (C) The Author(s) 2014

doi $10.1017 /$ bec.2014.18 
(Bowlby, 1973). This effect implies that children's IWMs and related appraisals should not vary across contexts or time. However, research does not fully confirm the theory that IWMs are merely a trait-like feature (Fraley, 2002). More specifically, it has been observed that attachment-related appraisals change when people are asked to recall a moment when they felt secure, anxious, or avoidant (e.g., Rowe \& Carnelley, 2003). This procedure seems to momentarily activate attachment states that override attachment traits, altering individuals' perceptions, attachment-related appraisals, and support-seeking behaviours (Baldwin, Fehr, Keedian, Seidel, \& Thomson, 1993; Baldwin, Keelan, Fehr, Enns, \& Koh-Rangarajoo, 1996; Gillath and Shaver, 2007). Of particular importance is a diary study in adults by Davila and Sargent (2003). Their study showed that experiencing interpersonal loss (i.e., loss of emotional support, closeness and affection, friendship/companionship, and trust) temporarily decreases state attachment security.

Given this evidence of state-variability in attachment, an important question is whether and how state attachment variability is related to trait attachment and, thus, to the content of the IWM. In the current article, we argue that variability in state attachment is moderated by trait attachment. We claim that variation in attachment-related appraisals in response to negative interactions with the attachment figure should be a function of trait attachment. This hypothesis was built on the recent finding that secure IWMs at least partly consist of a cognitive script, named a secure base script (Waters \& Waters, 2006). Like all cognitive scripts, this secure base script is a knowledge structure that consists of expected chains of behaviours, actions, and events. More specifically, this secure base script consists of three elements: (1) when a child is confronted with a distressing event, he or she appeals for help or the parent detects the child's distress; (2) the parent provides help, comfort and affect regulation that is effective in overcoming the difficulty; (3) the parent and child pair return to (or initiate new) constructive interaction (Waters \& Waters, 2006). Previous research has demonstrated that the secure base script is linked with increased support-seeking behaviour (Waters, Brockmeyer, \& Crowell, 2013) and with decreased psychopathology (Waters, Bosmans, Vandevivere, Dujardin, \& Waters, 2014). Most importantly, longitudinal research confirms that the secure base script explains the longitudinal stability of attachment (Steele et al., in press). This indicates that the secure base script underlies trait attachment.

Our hypothesis that trait attachment moderates variability in state attachment is based on the fact that cognitive scripts assimilate new information (e.g., Beck, 1964). Assimilation occurs because scripts alter or bias the cognitive processing of script-relevant information in conformity with the script's content (Baert, Koster, \& De Raedt, 2011). Consequently, in the context of attachment, Waters and Waters (2006) stated the following: 'If secure base support has been consistent and coherent, the script should be complete, well consolidated, and readily accessible in relevant 226 situations. If secure base support has been inconsistent, incomplete, or ineffective, the script should be less well configured and possibly less accessible' (p. 188). In other words, a secure base script should be reflected in consistent appraisals about attachment relationships. This means that children with a secure base script should show stable state attachment appraisals. Stability implies that state attachment should not be affected by, for example, occasional conflicts with attachment figures, because scripts assimilate script-incongruent information. Instead, children without a secure base script should not be able to assimilate script-incongruent information. This would 
increase the likelihood that insecurely attached children's state attachment appraisals fluctuate in response to occasional conflicts with their mother.

Little research has explicitly focused on the role of assimilation in the interplay between trait and state attachment. However, the diary study of Davila and Sargent (2003) touched upon this assimilation hypothesis. They investigated whether the effect of life events on changes in state attachment was moderated by trait security. Surprisingly, these authors concluded that state and trait attachment are independent. This apparent contradiction might be the result of Davila and Sargent's (2003) operationalisation of state and trait attachment. First, their measures of daily state attachment were simple sums of different items of an attachment scale designed to measure trait attachment. However, they did not check the scale's structure at the state level. The fact that a questionnaire has good psychometric properties when used for measuring trait differences does not say much about its performance when used at the state level. Hence, it was not possible to rule out that the absent association between trait and state attachment in their study was the result of inadequate operationalisation of state attachment. Consequently, new research should also investigate the state attachment scale's structure. Second, Davila and Sargent (2003) acknowledged that their study was limited because their measure of trait attachment did not really tap into attachment security versus insecurity. Instead, they measured anxiety of abandonment and comfort with intimacy. Consequently, a study measuring trait attachment by means of attachment questionnaires might provide a more appropriate test of the assimilation hypothesis.

\section{The Current Studies}

Two multiple day diary studies were carried out to test three predictions derived from the assimilation hypothesis: (1) more secure trait attachment should be related to less variable daily state attachment appraisals; (2) occurrence of conflicts with the attachment figure should be linked to variability in daily state attachment appraisals; and (3) this association should be stronger in children with less secure trait attachment appraisals. Study 1 aimed to investigate the first prediction, while Study 2 aimed to replicate Study 1 and to investigate the second and third predictions.

The current studies were designed to overcome the abovementioned limitations of Davila and Sargent's (2003) study. First, optimal state attachment estimates were obtained by applying multilevel simultaneous component analysis (MLSCA; Timmerman, 2006) to the diary data. This is a powerful statistical strategy that more clearly disentangles trait and state (attachment) components in diary data and that provides insight into the quality of the state attachment scale's structure. Therefore, this statistical approach should offer a better test of the current study's hypotheses. Second, to investigate the impact of trait attachment, widely used middle childhood questionnaires to measure trust, attachment anxiety, and attachment avoidance were used. Finally, these hypotheses were tested in late middle childhood. At this age, interactions with parents have an important impact on IWM development (e.g., Bosmans, Braet, Van Leeuwen, \& Beyers, 2006; Doyle \& Markiewicz, 2005). Therefore, late middle childhood should be a particularly interesting age group to look at the interplay between trait attachment, state attachment and the occurrence of parentchild conflicts. Although both parents are considered equally important attachment figures at this age, we assumed that the investigated basic attachment processes are 
independent of the parents' gender. Therefore, we minimised the burden on the participating children by limiting the diary questions to questions about mother.

\section{STUDY 1 \\ Method}

\section{Participants and Procedure}

Participants were recruited with the use of flyers, which were distributed in several schools and youth movements as part of a broader study on environmental influences in preadolescent boys and girls. Inclusion criteria were: aged from 9 to13 years and having access to a computer (with internet) at home. Children/parents who were interested in participating could write their personal data (name, telephone number) on the flyer and return it to the school/youth movement where an assistant would pick it up. Next, children/parents who returned the flyer were contacted by telephone by the research assistant, who explained the entire procedure of the study. They were told that the purpose of the study was to examine environmental influences - for example, the influence of the media - on the behaviour and thoughts of preadolescent boys and girls. They were also informed that the study had two main parts: the first part entailed the children keeping an online diary for 7 consecutive days (reporting on their daily habits, such as sleeping, eating and hobbies, and on interactions with parents and peers). This part would take about 15 minutes a day. The second part entailed a laboratory experiment (computer task) at the faculty. If they still agreed to participate, they received a personal code (by which the child could log on for 7 days to a secure page to complete his/her online diaries). Children filled out a trait attachment measure on day 1 , and the state attachment diaries on days 2 to 6 . The state attachment diaries were filled out at home before going to bed. On day 7, children filled out the trait attachment questionnaire again. On day 4 , they were invited to the lab to conduct an experiment that was not related to the current study. In this experiment, the influence of watching images representing the current thinness ideal on children's body satisfaction and eating behaviour was examined. Therefore, children were randomly assigned to either the experimental condition where they viewed 15 images of thin people, or to the control condition where they viewed 15 images of people with normal body composition. Afterwards, body satisfaction was assessed and children were presented a snack buffet. In total, 56 children were recruited. However, for two children data were incomplete, so the final sample consisted of 54 children ( 20 boys and 34 girls) with a mean age of 10.93 years $(S D=1.49$, range $9-13$ years $)$. Written informed consent was obtained from the parents, and written assent was obtained from the children as well. The local ethics committee approved the study design.

\section{8}

\section{Materials}

Attachment. Children completed an adapted version of the Experiences in Close Relationships Scale - Revised (ECR-R; Fraley, Waller, \& Brennan, 2000, adapted for children as the ECR-RC by Brenning et al., 2011) on day 1 and on day 7 to measure trait attachment towards the mother. The ECR-RC assesses the two dimensions central in attachment-related affect regulation: Attachment Anxiety and Avoidance. Attachment Anxiety is measured with 18 items tapping into feelings of fear of abandonment and strong desires for interpersonal merger (e.g., 'I worry about 


\begin{tabular}{|c|c|c|c|c|}
\hline \multirow[b]{2}{*}{ Appraisal: 'At this moment, I feel that ...' } & \multicolumn{2}{|c|}{ Study 1} & \multicolumn{2}{|c|}{ Study 2} \\
\hline & Between & Within & Between & Within \\
\hline $\begin{array}{l}\text { Trust } 1:{ }^{\prime} \ldots \text { my mother pays attention to } \\
\text { me.' }\end{array}$ & .71 & .28 & .61 & .43 \\
\hline $\begin{array}{l}\text { Trust } 2:{ }^{\prime} \ldots \text { I can count on my mother when } \\
\text { I am having a problem.' }\end{array}$ & .74 & .33 & .43 & .61 \\
\hline Trust 3: '.. I get along well with my mother.' & .67 & .38 & .33 & .65 \\
\hline $\begin{array}{l}\text { Anxiety } 1:{ }^{\prime} \ldots \text { if I show my mother that I } \\
\text { love her, I am afraid that she does not love } \\
\text { me as much as I love her.' }\end{array}$ & -.24 & -.56 & -.14 & -.13 \\
\hline $\begin{array}{l}\text { Anxiety } 2:{ }^{\prime} \ldots \text { I am afraid that my mother } \\
\text { likes me less than other children.' }\end{array}$ & -.47 & -.58 & -.20 & -.45 \\
\hline $\begin{array}{l}\text { Anxiety } 3:{ }^{\prime} . . . \text { my mother would not love } \\
\text { me anymore, if she knew what I really } \\
\text { thought and felt.' }\end{array}$ & -.42 & -.58 & -.29 & -.32 \\
\hline $\begin{array}{l}\text { Avoidance } 1:^{\prime}{ }^{\prime} \ldots \text { I prefer to solve my } \\
\text { problems on my own.' }\end{array}$ & -.70 & -.23 & -.65 & -.30 \\
\hline $\begin{array}{l}\text { Avoidance } 2: \text { ' ... I would rather not ask my } \\
\text { mother for help.' }\end{array}$ & -.71 & -.33 & -.61 & -.31 \\
\hline $\begin{array}{l}\text { Avoidance } 3: \text { ' } \ldots \text { it does not help me to talk } \\
\text { with my mother.' }\end{array}$ & -.59 & -.35 & -.52 & -.27 \\
\hline
\end{tabular}

being abandoned by my mother'). Attachment Avoidance is measured with 18 items tapping into discomfort with closeness, dependence, and intimate self-disclosure (e.g., 'I prefer not to show to my mother how I feel deep down'). Items are rated on a 7point Likert scale ranging from 1 (strongly disagree) to 7 (strongly agree). Both subscales have strong internal consistency and validity (Brenning et al., 2011). Before the registration period, the Cronbach's $\alpha$ s of the ECR-RC in this study were .73 and .91 for Attachment Anxiety and Avoidance; after the registration period, Cronbach's $\alpha$ s amounted to .90 and .95 .

Diary data. To measure daily attachment-related appraisals regarding mother, a diary was developed asking children daily to rate nine items on a Visual Analogous Scale $(100 \mathrm{~mm})$. These nine items are shown in Table 1 . All items had the same stem: 'At this moment, I feel that ...'. The nine items were selected with the goal of having three items that reflect trust in maternal support (e.g., '... I can count on my mother if I encounter a problem'), three items that measure anxious attachmentrelated appraisals (e.g., '... my mom likes me less than other children'), and three items that measure avoidant attachment-related appraisals (e.g., ' ... I would prefer not to ask my mother's help').

\section{Plan of the Analysis}

State attachment scores were obtained by applying MLSCA (Timmerman, 2006; Timmerman, Ceulemans, Lichtwarck-Aschoff, \& Vansteelandt, 2009), an extension of standard principal component analysis to multilevel data; in this case, days nested 
within children. In MLSCA, the data are first split in a between-part, consisting of the mean appraisal scores of each child across the days, and a within-part, representing the daily deviations of these means. Subsequently, PCA analyses are performed on both the between- and within-parts. As such, MLSCA yields a between-component that summarises the differences between the children in mean state attachment level and a within-component that summarises the attachment differences across the days (state attachment fluctuations). Similar to standard PCA, the loadings of the attachmentrelated appraisals on these components indicate the extent to which the means of the children and their daily deviations on these appraisals correlate with the betweencomponent and within-component respectively. Note that it is possible to obtain multiple between- and within-components, but that we decided to retain one component only on the basis of interpretability and parsimony. Important for the current study, this analysis gives an indication of the quality of the state attachment measure. More specifically, the between-and within-loadings reveal which attachment appraisals better tap inter- and intra-individual differences in overall attachment. This pattern of loadings is taken into account when computing the between- and within-component scores, in that appraisals with a higher loading receive a higher weight.

The scores on the between-subject component reflect individual differences in mean state attachment across the days. Therefore, the between-subject component resembles trait attachment. The scores on the within-subject component are based on daily deviations from the participant-specific means. This way, these scores yields insight into variability in state attachment. More specifically, the scores on this component indicate how securely attached a child is on a particular day, in comparison to his or her mean state attachment across the days. Using the within-subject component scores as a dependent variable might provide a superior test of the hypothesis that trait attachment and occurrence of conflicts are related to daily variability in state attachment. To investigate our hypothesis, we examined the correlations between the variances of the within-component scores and the between-component and ERC-RC scores.

\section{Results}

The between- and within-loadings of the MLSCA solution are shown in Table 1. It can be concluded that both the between-component and within-component are characterised by positive loadings for the appraisals tapping trust in maternal support and negative loadings for the anxious and avoidant appraisals. Yet, it is striking that whereas the anxious appraisals have the lowest between-loadings in an absolute sense, they have the strongest within-loadings. This implies that the most systematic differences in attachment anxiety are situated at the daily level, whereas trust and avoidant attachment vary considerably between children. The same conclusion can

230 be drawn from the intraclass correlation coefficients in Table 2, that indicate for each appraisal how much of its variance is due to mean differences between the children. All in all, these data suggest that the state attachment scale's structure is of good quality and should provide a powerful test of the current study's hypotheses.

Correlation analysis showed that children's between-component scores and the variances of their within-component scores were significantly correlated, $r=-.53$, $p<.001$. This meant that children's state attachment varied less across the days when, on average, they had more trust in their mother. Moreover, the variance of the 
TABLE 2

Intraclass Correlation Coefficients for Study 1 and Study 2

\begin{tabular}{lll}
\hline & Study 1 & Study 2 \\
\hline Trust 1 & .60 & .44 \\
Trust 2 & .58 & .25 \\
Trust 3 & .49 & .23 \\
Anxiety 1 & .13 & .19 \\
Anxiety 2 & .28 & .11 \\
Anxiety 3 & .29 & .24 \\
Avoidance 1 & .75 & .54 \\
Avoidance 2 & .57 & .45 \\
Avoidance 3 & .36 & .49 \\
\hline
\end{tabular}

within-component scores was significantly predicted by Attachment Anxiety measured on day $1, r=.30, p<.05$, but not by Attachment Avoidance on day $1, r=.16$, $n s$. No correlations were found with trait attachment measured on day 7 , respectively $r=-.12$, ns, and $r=-.19$, ns.

\section{Discussion}

In line with the assimilation hypothesis, Study 1 demonstrated that children who reported more secure state attachment-related appraisals across the registration period were less likely to vary in their state attachment-related appraisals from day to day. Moreover, high trait attachment anxiety at day 1 was related to the amount of variance in state attachment as well. This finding suggested that trait attachment is relevant to understand variance in state attachment-related appraisals. In other words, children who were more securely attached and who were less anxious about mother's availability had more stable state attachment-related appraisals. This finding was in line with our claim that children who are securely attached assimilate their experiences during their interactions with mother in congruence with a secure base script.

Although this finding was promising, as it provided first support for the assimilation hypothesis, these results needed replication. Moreover, these data did not offer insight into whether variance in state attachment-related appraisals is meaningfully related to the events that occur during interactions with mother. Therefore, Study 2 was designed to replicate Study 1. In Study 2, children were also asked daily whether conflicts with mother had occurred. This allowed us to investigate whether variance in state attachment-related appraisals is, among others, driven by mother-child conflicts. Also, Study 1 was limited because no trait measure of trust in the availability of maternal support was included. Because the appraisal of trust should be most closely related to the secure base script, it seemed important to include such a measure to test whether within-subject variance in state attachment-related appraisals indeed reflects a mechanism related to the secure base script. Finally, only trait attachment anxiety, but not trait attachment avoidance, was significantly correlated with variance in state attachment in Study 1. Post-hoc, we proposed that this could have been caused by the fact that children were selected from the general population. Generally, these children 
are normally developing, which makes it hard to find meaningful correlations with risk factors of abnormal development. Therefore, we decided to collect a sample of at-risk children in order to increase the power of Study 2.

\section{STUDY 2 \\ Method}

\section{Participants}

Data was collected in 32 children (17 boys, 15 girls) with ages ranging from 10 to 12 years $(M=10.6$ years $)$. No data was missing. Most of these children $(75 \%)$ lived together with both biological parents, while $25 \%$ had divorced parents. All children had mother as a primary attachment figure during the first 3 years of their lives, lived with her, and reported attachment-related appraisals about her. Regarding parental level of education, $3.1 \%$ of the mothers had an elementary school degree, $43.8 \%$ had a high school degree, $37.5 \%$ had a post-high school technical training or a technical bachelor degree, and $15.6 \%$ had a master's degree. Furthermore, $3.1 \%$ of the fathers had an elementary school degree, $34.4 \%$ had a high school degree, $43.8 \%$ had a post-high school technical training or a technical bachelor degree, and $12.5 \%$ had a master's degree.

\section{Procedure}

To increase the likelihood that a relevant number of mother-child conflicts would occur during the period in which children filled out the diary, we aimed to select a sample of mother-child dyads that were more at risk of reporting daily conflict. Building on the finding that distress in mothers increases mother-child conflict (e.g., Stoneman, Brody, \& Burke, 1989), and building on the finding that mothers with physical complaints are known to be vulnerable for elevated distress (Watson \& Pennebaker, 1989), we invited children of mothers attending physiotherapy to participate in the study. Invitation letters were distributed to female patients of a physiotherapist.

Again, the questionnaires to assess general attachment-related appraisals were administered before the start of diary data collection. Children were then given a pen-and-paper version of the diary and asked to fill out the diary every evening before going to bed. To increase the amount of data-points, we used a 7-day diary instead of a 5-day diary. We considered collecting data over an even longer period, but we were concerned that increasing the registration period would decrease children's motivation to collaborate and would lead, for example, to missing data. This would have had a negative impact on the reliability of the data. Finally, at the end of the week, the questionnaires to assess general attachment-related appraisals were again administered. Again, written consent was obtained from the parents and assent was obtained from the children as well. The local ethics committee approved the study design.

\section{Materials}

Attachment. Two questionnaires were administered before and after the diary registration period, to assess children's general attachment-related appraisals regarding mother. As in Study 1, the ECR-RC was administered. The day before diary data were collected, Cronbach's $\alpha$ s were .75 and .74 for Attachment Anxiety and Avoidance 
respectively. The day after diary data were collected, Cronbach's $\alpha$ s were .66 and .74 for Attachment Anxiety and Avoidance respectively.

Furthermore, to assess trust in maternal support, children filled in the Trust subscale (10 items; e.g., 'I can count on my mother to help me when I have a problem') of the People In My Life Questionnaire (Ridenour, Greenberg, \& Cook, 2006). This questionnaire is a child-friendly version of the Inventory of Parent and Peer Attachment (Armsden \& Greenberg, 1987) and is designed to measure 10 - to 12-yearold children's attachment-related appraisals of attachment figures (Ridenour et al., 2006). This measure has been widely used and has good psychometrics (Allen, in press). Its validity is suggested, for example, by links with attachment figure utilisation, self-esteem, and parenting quality (e.g., Armsden \& Greenberg, 1987; Gullone \& Robinson, 2005). The Trust subscale was previously linked with maternal parenting behaviours and the attentional processing of mother (e.g., Bosmans, Braet, Koster, \& De Raedt, 2009). Before and after diary data were collected, the Trust subscale was adequately reliable ( $\alpha=.72$ and .75 respectively).

Diary Data. To assess children's daily attachment-related appraisals of mother, the same nine items were used as in Study 1. To assess the impact of mother-child conflicts on inter-individual differences in attachment-related appraisals throughout the week, children were daily asked to respond to the question 'How many times did you have a conflict with your mother today?'

\section{Results}

The between- and within-loadings are shown in Table 1 . The between component can be labelled as trust in maternal support versus avoidant attachment, and the within component as trust versus anxious attachment. Moreover, we again found that anxious attachment generally has more systematic variance within children than between, which is especially clear for the second anxiety appraisal; however, unlike Study 1 , this is also the case for two of the three trust items. This corresponds with the intra-class correlation coefficients, shown in Table 2. To assess the similarity of the between- and within-components of Study 1 and 2, we computed Tucker's congruence coefficient (Tucker, 1951), based on the between- and within-loadings of both studies. According to the guidelines of Lorenzo-Seva and ten Berge (2006), the between-components of Study 1 and Study 2 can be considered equal (congruence of .97), while the within-components can be considered similar (congruence of .86). Consequently, these data suggest again that the state attachment scale's structure is of good quality and should provide a powerful test of the current study's hypotheses.

Regarding the first research question, Table 3 shows that the findings of Study 1 could be replicated in Study 2. More specifically, the between-component scores of the children were again significantly associated with the variances of their withincomponent scores, $r=-.55, p<.05$. The association between trait Attachment Anxiety on day 1 and the within-component was replicated as well, $r=.37, p<$ .05. Contrary to Study 1, however, the variance of the within-component was now also correlated with trait Attachment Anxiety on day 7 and with trait Attachment Avoidance and trait Trust, independent of whether these last two trait measures were administered before or after the registration period.

To investigate the second research question, links between within-subject fluctuations and the occurrence of conflicts with mother were examined. The total number of conflicts that occurred during the registration period per child ranged from 0 to 13 
TABLE 3

Correlations Between the Between Child Component Scores, the Variances of the Within Child Component Scores and Trait Attachment Measures for Study 2

\begin{tabular}{lccllllll}
\hline & 1 & 2 & 3 & 4 & 5 & 6 & 7 & 8 \\
\hline 1. Between & 1 & & & & & & & \\
2. Within & $-.55^{*}$ & 1 & & & & & & \\
3. Trust Pre & .16 & $-.50^{* *}$ & 1 & & & & & \\
4. Trust Post & .20 & $-.46^{* *}$ & $.35^{*}$ & 1 & & & & \\
5. Anxiety Pre & -.16 & $.37^{*}$ & -.28 & -.20 & 1 & & & \\
6. Anxiety Post & -.21 & $.35^{*}$ & -.12 & -.25 & $.66^{* * *}$ & 1 & & \\
7. Avoidance Pre & $-.55^{* * *}$ & $.70^{* * *}$ & $-.49^{* *}$ & $-.40^{*}$ & $.56^{* * *}$ & $.33^{\dagger}$ & 1 & \\
8. Avoidance Post & $-.50^{* * *}$ & $* .55^{* * *}$ & -.11 & $-.49^{* *}$ & .26 & $.47^{* *}$ & $.62^{* * *}$ & 1 \\
\hline
\end{tabular}

Note: Between = between child component scores, Within = variances of within child component scores, Pre $=$ measure before diary registration period; Post $=$ measure after diary registration period ${ }^{* * *} p<.001 ;{ }^{* *} p<.01 ;{ }^{*} p<.05 ;{ }^{\dagger} p<.07$

$(M=1.66 ; S D=2.68)$. Omitting the child who reported 13 conflicts with mother did not alter the results, so all analyses are reported on $n=32$. The correlation between children's within-component scores, measuring state attachment or daily deviance from their mean level appraisals, and number of conflicts that occurred the same day was significant, $r=-.15, p<.05$. Children who reported a conflict reported less secure state attachment appraisals compared to their mean level appraisals. Note that the total number of conflicts that occurred during the registration period was not related to the between-component, $r=-.13, n s$, and could not be predicted from children's trait attachment scores before the registration period (ps $>.27$ ).

Finally, to investigate the third research question, the moderating effect of trait attachment measures on the association between number of conflicts experienced and daily change in state attachment was studied. First, correlations were calculated per participant between the within-component scores and number of experienced conflicts. Further analyses were carried out for 17 participants, relating these correlations to the trait attachment measures. For the remaining participants, correlations could not be calculated as a result of lack of variance over days in the occurrence of conflicts or in the reported attachment appraisals. Table 4 shows that children's daily appraisals regarding mother are more related to the number of conflicts that occurred during the same day if they score high on Attachment Anxiety and Avoidance, independent of whether trait attachment was measured before or after the registration period. For Trust, the effects were in the predicted direction, but did not reach significance (Trust after the registration period reached $p=.12$ ).

\section{4}

\section{Discussion}

The results of Study 2 provided additional support for the hypothesis that children who have more trust in the availability of maternal support assimilate experiences during daily interactions in line with the content of a secure base script. The findings of Study 1 were replicated and expanded.

Replicating Study 1, children who reported to have higher mean secure state attachment-related appraisals across the registration period were less likely to vary 


\section{TABLE 4}

Correlations Between Trait Attachment

Measures and the Subject-Specific

Correlations Between Number of

Conflicts and Within Child Component

Scores

\begin{tabular}{lc}
\hline 2. Trust Pre & -.23 \\
3. Trust Post & -.39 \\
4. Anxiety Pre & $.55^{*}$ \\
5. Anxiety Post & $.58^{*}$ \\
6. Avoidance Pre & $.61^{* *}$ \\
7. Avoidance Post & $.70^{* *}$ \\
\hline
\end{tabular}

Note: Pre $=$ measure before diary

registration period; Post $=$ measure after

diary registration period

${ }^{* *} p<.01 ;{ }^{*} p<.05$

in their state attachment-related appraisals from day to day. Also, data from Study 2 again showed that variability in state attachment-related appraisals was related to trait attachment-related appraisals. In Study 2, these correlations were more explicit. Not only was the previously found effect of anxious attachment replicated, but now an effect of trust and avoidant attachment was also found. Moreover, this effect was found for trait attachment both before and after the registration period. These effects indicated that variability in state attachment-related appraisals was significantly lower for children who trusted in their mother's availability, and who were less anxious or avoidant at trait level. This suggested that securely attached children were more stable in their state attachment-related appraisals, while insecurely attached children were more volatile. This finding can be interpreted as supporting the assimilation hypothesis. More specifically, it appeared that only securely attached children had a secure base script that allowed them to encode experiences during interactions with attachment figures in line with the content of that script. Insecurely attached children did not seem to have a fixed script regarding their attachment figure, as their state attachment-related appraisals varied more on a day-to-day basis.

Expanding Study 1, Study 2 provided further evidence supporting the assimilation hypothesis. First, data suggested that variance in state-attachment appraisals was conditional upon the occurrence of conflicts during interactions with mother. Compared to the average level of state attachment-related appraisals reported during the registration period, conflicts were associated with more negative state attachmentrelated appraisals. Instead, these appraisals became more positive in the absence of conflict. This finding suggested that variance in state attachment-related appraisals reflected attachment-relevant interactions with mother. Second, and most importantly, the association between conflicts and variance in state attachment-related appraisals was moderated by trait attachment. Again, this finding supported the assimilation hypothesis, as children's state attachment-related appraisals were less affected by absence/occurrence of conflicts when their trait attachment-related appraisals suggested that they had a secure base script. When children's trait attachment-related appraisals suggested that they lacked a secure base script, the occurrence of conflicts had a stronger impact on their state attachment-related appraisals. In summary, these 
findings suggested that securely attached children assimilated negative events in such a way that these events did not alter their state appraisals of the attachment relationship. Insecurely attached children could not assimilate these events, which made their state appraisals seem more dependent upon their day-to-day experiences.

The current study's finding that conflict negatively affected state attachment replicated Davila and Sargent's (2003) finding that negative life events decreased state attachment security. Yet, the correlations between trait and state attachment and the finding that trait attachment moderates the effect of conflicts on variability in state attachment contradicted Davila and Sargent's (2003) conclusion that state and trait attachment should be considered independent components of the attachment system. It is not possible to exclude that this discrepancy reflects different processes in middle childhood and adulthood. However, it seems reasonable to argue that it is the result of three differences in the specific setup of the current studies: (1) Analysing diary data with MSCLA allowed to better partial out state attachment-related variation. Consequently, all current analyses were carried out controlling for the possibly obscuring effect of between-subject differences. This could have increased the power of the analyses, resulting in a better test of the assimilation hypothesis. (2) The content of the questionnaires Davila and Sargent (2003) used to measure trait attachment was similar to the content of both their daily measures of negative life events. We proposed that this could have obscured interaction effects. In line with this assumption, the current study suggests that the use of actual trait attachment measures and the approach to measure daily occurrence of conflicts might have been useful to reveal significant interactions. (3) Using a middle childhood sample might have increased the power as well. Children's IWMs are under more development compared to adults' IWMs (Fraley \& Brumbaugh, 2004). So, the current samples' age might have made it easier to detect the interplay between state and trait components.

\section{General Discussion}

The current studies' aim was to investigate the interplay between trait and state attachment, testing the assimilation hypothesis. This hypothesis was derived from the recent finding that securely attached individuals' IWMs consist at least partly of a secure base script (Waters \& Waters, 2006). Two multiple-day diary studies were carried out. Results supported the predictions derived from the assimilation hypothesis: (1) more secure trait attachment-related appraisals decreased variance in daily state attachment appraisals; (2) occurrence of conflicts with the attachment figure was linked to variance in daily state attachment appraisals; but (3) this association was modulated by trait attachment-related appraisals. In the following paragraphs, we will discuss the theoretical relevance of these findings, the studies' limitations, and some clinical implications.

\section{Theoretical Implications}

The current studies provided an important addition to a growing body of literature that suggests that understanding the IWM requires studying attachment from a cognitive schema perspective. This was already postulated by Bretherton (1990), and some previous studies had hinted that such a cognitive schema conceptualisation of IWMs might be useful to understand the attachment system (e.g., Baldwin et al., 1993). However, it was Waters and Waters' (2006) observation that individuals organise attachment information in a schema-like manner that seemed to 
instigate a new line of research in which IWMs are studied from a cognitive schema perspective. Ever since, research has increasingly confirmed that IWMs have schemarelated content and function according to predictions derived from cognitive schema theory.

On a content level, Waters et al. (2013) showed that links between adult attachment representations and secure base behaviour are explained by adults' secure base script knowledge. In the same vein, Bosmans, Braet, and Van Vlierberghe (2010) provided evidence that cognitive schemas explain the link between attachment and psychopathology. On a functional level, cognitive schemas are known to alter the processing of schema-relevant information. Recent research confirms that attachmentrelated appraisals modulate individuals' attention for, interpretation of, and recollection of attachment-related information such that novel information is processed in line with the content of IWMs (Bosmans, De Raedt, \& Braet, 2007; Bosmans et al., 2009; Dykas \& Cassidy, 2011).

The current evidence that securely attached children assimilate conflicts with mother in such a way that they do not alter their attachment-related appraisals provides additional support for the assumption that IWMs behave in line with assumed cognitive schema characteristics. In fact, it may be that these findings should be understood as the result of the information processing biases that characterise attachment-related appraisals. Because children's processing of attachment-related information is biased towards a confirmation of their secure base script, objectively incongruent information (conflicts) might not be encoded as such. Although this is a promising hypothesis that could shed further light on the interplay between state and trait attachment components, this should be further tested in future research.

\section{Clinical Implications}

Attachment theory, as one of the only remaining 'big' theories developed halfway in the previous century, has had a huge impact on therapists' awareness of the important role of parent-child relationships in maladjustment. However, in spite of clear evidence demonstrating that insecure attachment is a transdiagnostic risk factor (e.g., DeKlyen \& Greenberg, 2008), leading therapeutic models such as cognitive behavioural therapy (CBT) have struggled to adequately incorporate attachment theory into assessment and treatment because of the theoretical vagueness of core constructs like the IWM (for a discussion of the lack of clarity of this construct, see, e.g., Bosmans et al., 2010; Waters \& Waters, 2006). The current study contributes to the clarification of this core construct, leading to specific recommendations to optimise attachment-related assessment and intervention.

With regard to assessment, the current studies suggest that the secure base script and the related trust in attachment figure care and support might be essential to concretely identify the quality of the attachment relationship. Moreover, the current studies suggest that it might be insufficient to assess these expectations at one time point: given the impact of concurrent interactions with parents, less securely attached children might overestimate their trust in attachment figure support. Although more research in larger and more pathological samples is needed, the findings suggest that a more sensitive approach to assess lack of trust might be to use repeated measures across a brief period and to look at the extent children fluctuate in their appraisal of their parent's availability. 
With regard to interventions, therapeutic approaches seldom focus on enhancing children's trust in attachment figure care and support. Instead, indirect approaches are used, focusing on improving parenting skills using parent management training (PMT, e.g., Golding, 2000). However, approaching attachment from a cognitive schema perspective has serious implications for the potential effectiveness of such PMT. It suggests that PMT might have a more limited effect than originally assumed because it is likely that less securely attached children might not have developed the information-processing biases that allow them to adequately encode changes in parental behaviour due to PMT (Bosmans et al., 2007, 2009). This hypothesis is in line with the finding that with the increasing age of targeted children, the effectiveness of PMT declines (Kazdin, 1995). This line of reasoning suggests that new approaches need to be developed to complement PMT in order to achieve higher effect sizes. One approach could be the use of cognitive bias modification (Macleod, Koster, \& Fox, 2009), which aims to alter the content of cognitive schemas by retraining the biases that accompany these schemas. Adding such a CBM component to the traditional treatment of child and adolescent psychopathology might prove to be a very powerful tool to substantially improve treatment effects through enhancing children's trust in attachment figure care and support.

\section{Limitations}

Although the current studies' results confirmed challenging hypotheses derived from strong theoretical assumptions, the current studies have some limitations that are important to note. Most importantly, trait attachment was measured using questionnaires. The use of attachment questionnaires has been criticised based on theoretical arguments. It has been argued that self-report is a less valid approach to measure attachment as it over-identifies security (Ainsworth, 1985), suggesting that only selfreported insecure attachment can be considered as valid and reliable. Contrary to this argument, the current results suggest that the attachment questionnaires revealed theoretically consistent distinct patterns of associations between the occurrence of conflict and changes in state attachment for secure versus insecure self-reported trait attachment in middle childhood. The current promising findings add to previous research that suggests that, compared to narrative measures, attachment questionnaires might more clearly capture attachment-related individual differences in middle childhood (Kerns, Brumariu, \& Seibert, 2011). This could be because, at this age, the outcome of narrative measures are more influenced by cognitive maturation than in adulthood. Nevertheless, given that assimilation should be function of the presence/absence of a secure base script (Waters \& Waters, 2006), it might be worthwhile for future research to measure secure base script knowledge using the middle childhood version of the secure base script test that is currently under construction (Waters et al., 2011).

238 Also, measuring occurrence of conflicts as a source of within-subject variance in state attachment might have some limitations. First, the distribution of the number of conflicts was skewed, with many zero responses. This could have various reasons. In the questionnaire it was not specified what was meant by 'conflicts'. Thus, a particular situation might have been seen by some children as a conflict whereas others might not have regarded it as such. Using a broad definition of conflicts while controlling for severity might increase variance in reported conflicts. In addition, the child-report of conflicts might have been influenced by assimilation processes as well. Less securely 
attached children might be more sensitive to experienced conflict or might better recall at the end of the day whether conflicts occurred. Nevertheless, no correlations were found between trait attachment scores and the occurrence of conflicts. This suggests that children's report of conflicts is independent of trait attachment. Furthermore, no instructions were given concerning the privacy of the children while filling out the diary. It is possible that the mother was nearby at that moment and that children therefore did not feel comfortable enough to report any conflicts that could have occurred that day.

Second, one could consider daily conflicts with mother as a minor source of relational distress. Such incidents might get more easily assimilated due to secure base scripts. The current study does not allow the conclusion that all sources of relational distress might be as easily assimilated, as it is not unlikely that experiences that are more threatening (e.g., loss or separation from attachment figures through divorce; Hamilton, 2000) for the attachment relationship lead to adjustment of IWM content (e.g., Sroufe, Egeland, \& Kreutzer, 1990). Answering such a research question with adequate power requires a longitudinal design with a large sample of children that are intensively followed.

Furthermore, the current studies' samples were rather small and the observation periods were limited. These limitations were especially at play in our test of our third prediction as the sample was reduced to $n=17$ due to lack of variance in occurrence of conflicts and/or state attachment. Hence, including larger samples and longer registration periods could be useful to increase variance to rule out that the effect is not a statistical coincidence.

Finally, one can question whether the current study allows drawing firm conclusions regarding causality. The analyses are correlational by nature, so it is not possible to argue that one variable caused the other variable. Although the longitudinal nature of the current study's design and the logical temporal order in which trait and state measures were administered does suggest some direction of effects, an important addition would be to use experimental paradigms to study this research question. For now, the current design has the advantage that it offers an ecologically valid insight in the interactions between trait and state attachment.

\section{Conclusion}

The current study aimed to examine variability in state attachment and its relations to trait attachment and conflicts with the attachment figure. Two studies were carried out. Diary reports of state attachment-related appraisals revealed that these appraisals reflected a between-subject and a within-subject component that are interrelated. Children who reported more secure attachment-related appraisals across the registration period varied less in their daily attachment-related appraisals. Moreover, variation within attachment-related appraisals was meaningfully related to the occurrence of conflict during interactions with mother: the occurrence of conflict coincided with less secure appraisals, while lack of conflict was associated with more secure appraisals. Importantly, the link between occurrence of conflict and fluctuations in state attachment-related appraisals was stronger for children who were less securely attached at the trait level. This suggested that trait and state attachment are meaningfully related. The current findings were in line with recent conceptualisations of IWMs as secure base scripts, because children with a secure 
base script assimilated negative interactions in congruence with the content of that script.

\section{Acknowledgments}

This work was supported by the Research Foundation Flanders (FWO), Belgium (G.B., grant number G.0934.12); and the Research Fund KU Leuven, Belgium (G.B., grant number OT/12/043), (G.B., grant number CREA/12/004).

\section{References}

Ainsworth, M.D.S. (1973). The development of infant-mother attachment. In B.M. Caldwell \& H.N. Ricciuti (Eds.), Review of child development research (vol. 3, pp. 1-94). Chicago, IL: University of Chicago Press.

Ainsworth, M.D.S. (1985). Attachments across the life span. The Bulletin of the New York Academy of Medicine, 61, 792-812.

Ainsworth, M.D.S., Blehar, M.C., Waters, E., \& Wall, S. (1978). Patterns of attachment: A psychological study of the strange situation. Hillsdale, NJ: Erlbaum.

Allen, J.P. (in press). Assessing attachment in adolescence. In E. Waters, B. Vaughn, \& H. Waters (Eds.), Measuring attachment. New York: Guilford.

Armsden, G.C., \& Greenberg, M.T. (1987). The Inventory of Parent and Peer Attachment: Individual differences and their relationship to psychological well-being in adolescence. Journal of Youth and Adolescence, 16, 427-454.

Baert, S., De Raedt, R., \& Koster, E.H.W. (2011). Modification of information-processing biases in emotional disorders: Clinically relevant developments in experimental psychopathology. International Journal of Cognitive Therapy, 4, 208-222.

Baldwin, M.W., Fehr, B., Keedian, E., Seidel, M., \& Thomson, D W. (1993). An exploration of the relational schemata underlying attachment styles: Self-report and lexical decision approaches. Personality and Social Psychology Bulletin, 19, 746-754.

Baldwin, M.W., Keelan, J.P.R., Fehr, B., Enns, V., \& Koh-Rangarajoo, E. (1996). Social cognitive conceptualization of attachment working models: Availability and accessibility effects. Journal of Personality and Social Psychology, 71, 94-104.

Beck, A.T. (1964). Thinking and depression: 2. Theory and therapy. Archives of General Psychiatry, $10,561-571$.

Bosmans, G., Braet, C., Koster, E., \& De Raedt, R. (2009). Attachment security and attentional breadth toward the attachment figure in middle childhood. Journal of Clinical Child and Adolescent Psychology, 38, 872-882.

Bosmans, G., Braet, C., Van Leeuwen, K., \& Beyers, W. (2006). Do parenting behaviors predict externalizing behavior in adolescence, or is attachment the neglected 3rd factor? Journal of Youth and Adolescence, 35, 373-383.

Bosmans, G., Braet, C., \& Van Vlierberghe, L. (2010). Attachment and symptoms of psychopathology: Early maladaptive schemas as a cognitive link. Clinical Psychology and Psychotherapy, 17, 374-385.

Bosmans, G., De Raedt, R., \& Braet, C. (2007). The invisible bonds: Does the secure base script of attachment influence children's attention towards their mother? Journal of Clinical Child and Adolescent Psychology, 36, 557-567.

Bowlby, J. (1969). Attachment. London: Penguin Books.

Bowlby, J. (1973). Attachment and loss: Vol. 2. Separation: Anxiety and anger. New York: Basic Books.

Brenning, K., Soenens, B., Braet, C., \& Bosmans, G. (2011). An adaptation of the experiences in close relationships scale-revised for use with children and adolescents. Journal of Social and Personal Relationships, 28, 1048-1072. 
Bretherton, I. (1990). Open communication and internal working models: Their role in the development of attachment relationships. In R. Thompson (Ed.), Nebraska Symposium on Motivation: Vol. 36. Socio-emotional development. Lincoln, NE: University of Nebraska Press.

Brumariu, L.E., \& Kerns, K.A. (2010). Parent-child attachment and internalizing symptoms in childhood and adolescence: A review of empirical findings and future directions. Development and Psychopathology, 22, 177-203.

Davila, J., \& Sargent, E. (2003). The meaning of life (events) predicts changes in attachment security. Personality and Social Psychology Bulletin, 29, 1383-1395.

DeKlyen, M., \& Greenberg, M.T. (2008). Attachment and psychopathology in childhood. In J. Cassidy \& P.R. Shaver (Eds.), Handbook of attachment: Theory, research, and clinical application (pp. 637-665). New York: Guilford Press.

Doyle, A.B., \& Markiewicz, D. (2005). Parenting, marital conflict and adjustment from early- to mid-adolescence: Mediated by adolescent attachment style? Journal of Youth and Adolescence, 34 , $97-110$.

Dykas, M.J., \& Cassidy, J. (2011). Attachment and the processing of social information across the life span: Theory and evidence. Psychological Bulletin, 137, 19-46.

Fraley, R.C. (2002). Attachment stability from infancy to adulthood: Meta-analysis and dynamic modeling of developmental mechanisms. Personality and Social Psychology Review, 6, 123-151.

Fraley, R.C., \& Brumbaugh, C.C. (2004). A dynamical systems approach to understanding stability and change in attachment security. In W.S. Rholes \& J.A. Simpson (Eds.), Adult attachment: Theory, research, and clinical implications (pp. 86-132). New York: Guilford.

Fraley, R.C., Waller, N.G., \& Brennan, K.A. (2000). An item response theory analysis of self-report measures of adult attachment. Journal of Personality and Social Psychology, 78, 350-365.

Gillath, O., \& Shaver, P.R. (2007). Effects of attachment style and relationship context on selection among relational strategies. Journal of Research in Personality, 41, 968-976.

Golding, K. (2000). Parent management training as an intervention to promote adequate parenting. Clinical Child Psychology and Psychiatry, 5, 357-371.

Gullone, E., \& Robinson, K. (2005). The Inventory of Parent and Peer Attachment - Revised (IPPA-R) for children: A psychometric evaluation investigation. Clinical Psychology and Psychotherapy, 12, 67-79.

Hamilton, C.E. (2000). Continuity and discontinuity of attachment from infancy through adolescence. Child Development, 71, 690-694.

Kazdin, A.E. (1995). Conduct disorders in childhood and adolescence (2nd ed.). Thousand Oaks, CA: Sage.

Kerns, K.A., Brumariu, L.E., \& Seibert, A. (2011). Multi-method assessment of mother-child attachment: Links to parenting and child depressive symptoms in middle childhood. Attachment and Human Development, 13, 315-333.

Lorenzo-Seva, U., \& ten Berge, J.M.F. (2006). Tucker's congruence coefficient as a meaningful index of factor similarity. Methodology, 2, 57-64.

MacLeod, C., Koster, E.H., \& Fox, E. (2009). Whither cognitive bias modification research? Commentary on the special section articles. Journal of Abnormal Psychology, 118, 89-99.

Mikulincer, M., \& Shaver, P.R. (2007). Attachment in adulthood: Structure, dynamics, and change. New York: Guilford Press.

Ridenour, T.A., Greenberg, M.T., \& Cook, E.T. (2006). Structure and validity of people in my life: A self-report measure of attachment in late childhood. Journal of Youth and Adolescence, 35, 1037-1053.

Rowe, A., \& Carnelley, K.B. (2003). Attachment style differences in the processing of attachmentrelevant information: Primed-style effects on recall, interpersonal expectations, and affect. Personal Relationships, 10, 59-75.

Sroufe, L.A., Egeland, B., \& Kreutzer, T. (1990). The fate of early experience following developmental change: Longitudinal approaches to individual adaptation in childhood. Child Development, 61, $1363-1373$. 
Steele, R.D., Waters, T.E.A., Bost, K.K., Vaughn, B.E., Truitt, W., Waters, H.S., Booth-Laforce, C., \& Roisman, G.I. (in press). Caregiving antecedents of secure base script knowledge: A comparative analysis of young adult attachment representations. Developmental Psychology.

Stoneman, A., Brody, G.H., \& Burke, M. (1989). Marital quality, depression and inconsistent parenting: Relationship with observed mother-child conflict. American Journal of Orthopsychiatry, $59,105-117$.

Timmerman, M.E. (2006). Multilevel component analysis. British Journal of Mathematical and Statistical Psychology, 59, 30 1-320.

Timmerman, M.E., Ceulemans, E., Lichtwarck-Aschoff, A., \& Vansteelandt, K. (2009). Multilevel component analysis for studying intra-individual variability and inter-individual differences. In J. Valsiner, P.C.M. Molenaar, M.C.D.P. Lyra, \& N. Chaudhary (Eds.), Dynamic process methodology in the social and developmental sciences (pp. 291-318). New York: Springer.

Tucker, L.R. (1951). A method for synthesis of factor analysis studies (Personnel Research section Rep. No. 984). Washington, DC: Department of the Army.

Waters, H.S., Scandariato, I., Waters, T., Bianchini, A., Horan, E., \& Bosmans, G. (2011, March). Middle childhood attachment narratives: Organized Around a secure base script? Poster presentation presented at the meeting of Society of Research in Child Development Biennal meeting, Montreal, Canada.

Waters, H.S., \& Waters, E. (2006). The attachment working models concept: Among other things, we build script-like representations of secure base experiences. Attachment and Human Development, 8, 185-197.

Waters, T.E.A., Brockmeyer, S.L., \& Crowell, J.A. (2013). AAI coherence predicts caregiving and care seeking behavior: Secure base script knowledge helps explain why. Attachment and Human Development, 15, 316-331.

Waters, T.E.A., Bosmans, G., Vandevivere, E., Dujardin, A., \& Waters, H.S. (2014). Secure base representations in middle childhood. Manuscript under review.

Watson, D., \& Pennebaker, J.W. (1989). Health complaints, stress, and distress: Exploring the central role of negative affectivity. Psychological Review, 96, 234-254. 